\title{
José María Pozuelo Yvancos, Poéticas de poetas. Teoría, crítica y poesía, Madrid, Biblioteca Nueva, 2009, 298 pp.
}

Desde que en 1979 publicara Pozuelo Yvancos su primer libro, El lenguaje poético de la lírica amorosa de Quevedo, nunca dejó de prestar atención a la poesía, como prueba este libro, Poética de poetas, que recoge los artículos sobre el asunto escritos entre 1991 y 2007 con un sentido de unidad ("la idea de poesía que puede traducirse de lo escrito por los poetas mismos") que conjuga las tres facetas que expresa la segunda parte del título: Teoría, crítica y poesía. Al ámbito de la teoría pertenece el capítulo inicial e introductorio, “Teoría de la lírica”, que considero esencial para un entendimiento moderno de los géneros líricos $\mathrm{y}$, más concretamente, de la compleja problemática de la enunciación lírica. La pregunta de Pozuelo es: “Ejerce la lírica una especificidad enunciativa?". No es fácil resumir tal problemática, históricamente unida a la teoría de los géneros, que ha atribuido a la lírica una enunciación en primera persona como expresión directa de la subjetividad del poeta, mezclando, como señala Pozuelo, criterios de modalidad enunciativa y criterios de contenido. Pozuelo Yvancos centra su postura en "la dificultad para definir el género lírico desde el estatuto enunciativo, no sólo por su enorme variabilidad histórica, sino por la falta de especificidad de las formas de la primera persona enunciativa, que le son predominantes"; de ahí que pretenda -desde los contextos comunicativos aportados por la Semiótica y la Lingüística- superar el corsé tradicional de la "enunciación lírica" a favor de un "espacio enunciativo propio" de la lírica que conlleva la no especificación tanto de una situación de habla como de un contexto situacional de objetos, acciones, espacios y tiempos; al contrario, el texto lírico crea "espacios de indeterminación enunciativa" que requieren un lector que acepte tales vacíos contextuales y situacionales "como un esquema discursivo necesario para el tipo de recepción y para la consecución de los fines de tal discurso". De este modo, la especificidad de la enunciación lírica residiría en la creación de un espacio de enunciación o "esquema de discurso" (Stierle) propio caracterizado por dos rasgos inextricablemente unidos: la "presentez" como tiempo de la vivencia lírica emisora y receptora ("la poesía lírica convierte los estados de hecho, las realidades, los objetos e incluso las personas que en ella se convocan en presencias actuales" reactivadas en el tiempo o experiencia actual de la lectura); y para que eso ocurra, "la relación sujeto-objeto deviene emergencia del sujeto o realización plena de su conciencia reflexiva, refleja", por medio de la cual tú y él son, en ese espacio enunciativo, "imágenes proyectadas ficticiamente del propio yo, representaciones de la conciencia íntima del sujeto". Como concluye Pozuelo, "en ese espacio de enunciación es fundamental la intrínseca comunicabilidad y traslación del yo al tú, como otro yo, y del tú al yo: ese espacio es el que permite la identificación del lector [...], la identificación del tú no sólo con lo dicho, sino con la experiencia del yo en lo dicho, en el acto de su vivencia, que coincide con la ejecución de su lenguaje, con el nacimiento del poema y con el acto de su lectura". Como puede intuirse, la complejidad del asunto y de la propia dilucidación 
teórica debe llevar a la lectura del capítulo en su totalidad, pues lo aquí reseñado no es más que un pálido reflejo de su contenido.

Al capítulo inicial siguen otros doce que podríamos considerar en dos apartados diferenciados cronológicamente, pues los siete primeros se centran en poetas de la llamada generación del 27 y los restantes en poetas de distintas promociones posteriores, de la posguerra (Hierro) a la generación del cincuenta (Gil de Biedma), por usar una extendida denominación, y de los novísimos (Talens) a uno de los llamados poetas-isla (Urrutia) o a otro de una generación más joven (Sánchez Rosillo).

Dos capítulos se refieren al Pedro Salinas crítico-ensayista; uno de ellos se titula "Pedro Salinas y su defensa del lenguaje"; el otro, que voy a reflejar en esta recensión, "Pedro Salinas, crítico literario". En cuanto crítico, Pozuelo incluye a Salinas en el gran proyecto intelectual y crítico que alentó la generación de Ortega y que partió de los grandes maestros del 98. Y en esa filiación "inequívoca, consciente y explícita" hay que situar, como muestra concreta de aquel proyecto intelectual, los ensayos de Salinas, en los que predomina, más que el historiador de la literatura, la "reflexión de un lector" con enorme caudal de lecturas; un lector que buscaba en sus ensayos, ante todo, la comunicación con otros lectores u oyentes (muchos ensayos nacieron como conferencias), con una dimensión pedagógica conectada con el espíritu que animó a los maestros de las dos generaciones antes nombradas: "Salinas concebía su producción ensayística las más de las veces como una misión intelectual" responsable en relación con la educación de la sociedad contemporánea desde la literatura. El profesor Pozuelo Yvancos estudia con datos la conexión del poeta del 27 (sólo como poeta puede ser adscrito a ella) con el proyecto intelectual habido en España en los treinta primeros años del siglo y conectada en el caso de Salinas y otros intelectuales con el Centro de Estudios Históricos, aspecto de sumo interés que no podemos sino mencionar en estas líneas. Pozuelo traza después los principales conceptos de la crítica literaria de Salinas: la tradición (con proximidades y discrepancias respecto a T.S. Eliot), la poesía como creación original, en confluencia con la estilística idealista de Vossler, y el "tema vital" como eje estructurador de una obra, aspecto de gran interés en el que aquí no podemos detenernos. Pozuelo concluye señalando que si el fuerte idealismo y el personalismo individualista como explicación del fenómeno poético puede ser hoy una limitación del sistema crítico de Salinas, es también su grandeza, pues alienta en sus páginas un propósito humanista: "la razón vital última de su crítica era el hombre".

Es magnífico el capítulo dedicado a "La poética y la crítica literaria de Jorge Guillén", en el que Pozuelo analiza primeramente la coherencia entre la escritura crítica y la escritura poética guilleniana, y en la que advierte honda capacidad reflexiva vertida en el análisis de escrituras ajenas, análisis que viene a coincidir con su propio concepto de poesía, como cuando aplica a Góngora vocablos como "construcción" o "arquitectura", muy apropiados para el arte del poeta barroco, pero también para la poesía de Guillén, como propio de los dos es también la unión de 
inteligencia y sensorialidad que Guillén atribuye al poeta cordobés. Por otro lado, Pozuelo aclara las aportaciones guillenianas a la crítica del momento, que se manifiestan en su actitud antirromántica y antipositivista y en esa visión de "Jano intelectual" en equilibrio entre lo clásico y lo vanguardista, actitud renovadora que denuncia lo que hay de consabido en uno y otro bando, manteniendo, además, un elitismo intelectual de carácter europeo y universalista. Bajo la influencia de Valéry, Eliot y la fenomenología, la postura crítica de Guillén desemboca en su conocida "poética del poema" (no de la poesía), "donde cobran unidad los diferentes análisis críticos de Guillén" y sus ideas sobre la construcción del poema.

En torno a las poéticas de la celebrada Antología de Gerardo Diego discurre otro de los capítulos, analizando su heterogeneidad, aunque del conjunto deduzca el analista que es más avanzada y comprometida la obra creativa de los poetas que la reflexiva, lastrada por un "elitismo" de la creación poética y su lenguaje "inefable", frente a actitudes más renovadoras (Guillén, Diego) o de mayor hondura reflexiva (A. Machado). A uno de los poetas de dicha antología; Vicente Aleixandre, dedica el profesor Pozuelo dos capítulos de su libro: uno sobre Los encuentros; el otro, al que me voy a referir con la brevedad necesaria, es un acercamiento a "El poeta", composición que supone un extraordinario punto de arranque teórico sobre las limitaciones de la investigación sobre la lírica (dispersada en poetas y poemas concretos y ceñida a cuestiones formales) y las razones que lo explican, en las que no podemos detenernos. Expone Pozuelo los tópicos sobre la lírica de la teoría actual, de la pragmática de la lírica en concreto: el de "mayor significación" o pluralidad significativa, el de la absolutización de la experiencia con el lenguaje y el de los roles pragmáticos (autocomunicación), tópicos que ilustra el espléndido análisis de "El poeta" sirviéndose de los instrumentos conceptuales prestados por la Lingüística textual.

Uno de los capítulos fuertes de Poéticas de poetas es el dedicado a la exposición, análisis e interpretación de la crítica literaria de Luis Cernuda, que crea su tradición propia a partir del Romanticismo europeo, ajena a la línea de continuidad de la poesía española, algo que el propio Pozuelo resume: “Cernuda se siente extranjero, no encuentra su lugar en la tradición poética hispana y lo repite una y otra vez. Ese carácter de extrañamiento, de enajenación respecto a su cultura, es una constante en la que conviene detenerse, porque ofrece muchos perfiles y todos juntos dibujarán bien el rostro de su pensamiento poético y crítico. Y el caso es que ese pensamiento estará también enraizado en su propia personalidad humana y social. El sentimiento de extrañamiento, de ser ajeno, afluye por doquier en sus reflexiones y es una urdimbre bien conocida de su propio tejido personal". Acudo también a las palabras de Pozuelo para sintetizar lo que fue la obra reflexiva de "un espíritu crítico muy agudo, de lector sagaz": “La crítica literaria de Cernuda tantas veces arbitraria, alguna vez desgarrada, siempre sincera y veraz, irreductible a componendas de academia, es un hermoso testimonio del hombre, pero sobre todo es un mapa literario de poeta que instruyó en sus viajes críticos algunas de las etapas 
que transitó luego su poesía, esa poesía que anudada en el deseo puede hacer más grande la realidad de los lectores".

Con el capítulo noveno comienzan los estudios sobre poetas de las distintas generaciones que se sucedieron a partir de 1939, empezando por el análisis de un poema de José Hierro y siguiendo con el trazado de la poética de Gil de Biedma, poniendo de relieve "las vías de intercomunicación entre su actividad teórica, su personalidad crítica y su poesía", es decir, la interrelación de "teoría y creación, de conciencia y obra, de reflexión y actividad poética". Ir más allá en esta mera mención de la exposición de Pozuelo Yvancos supondría desfigurar vanamente un complejo de ideas que construyen el mapa del pensamiento poético del lúcido poeta catalán.

Otro de los capítulos se dedica al alzado de la poética de Jenaro Talens, que Pozuelo extiende a la poética novísima, poniendo de relieve su modernidad (lecturas intensas de Kristeva, Lacan, Mallarmé, Mao, etc.). La originalidad de Talens consiste en allegar al poema vocabulario y conceptos de la semiótica, la teoría literaria y las ciencias del lenguaje para construir una lúcida poética de la opacidad del signo, de su intransitividad y del "sujeto vacío", imagen de la ruptura de la identidad del poeta.

Poéticas de poetas finaliza con sendos capítulos dedicados respectivamente al análisis de $E l$ grado fiero de la escritura (1977), de Jorge Urrutia, y de la poesía completa de Sánchez Rosillo, que apareció en 2003 con el título Las cosas como fueron, a lo que hay que añadir el poemario La certeza, publicado en 2005. Destaca Pozuelo la unidad de la obra toda del poeta murciano, cifrada en tres rasgos que sólo citaremos: la centralidad en el yo como origen y desembocadura de toda experiencia, la línea clara de su poética y la poetización del instante a que propende.

Poéticas de poetas uno de los libros más lúcidos que conozco sobre poetas del siglo XX en cuanto sustentadores directos o indirectos, es decir, de manera explícita en sus ensayos y críticas o implícita en sus obras creativas, de un pensamiento poético que ejerce de guía, en los casos mejores, de su propia creación lírica y que, en todo caso, nos ayudan a comprenderla mejor. No es extraño que sea así, puesto que el profesor Pozuelo es propietario de un pensamiento capaz de abarcar campos teóricos de gran amplitud, entre los que se mueve con soltura, campos, por otra parte, que tienen -por usar un adjetivo caro al autor- un formidable cimiento tanto en las poéticas clásicas como en las poéticas y teorías más fecundas del siglo XX y del momento presente. Añádase una extraordinaria capacidad de análisis en continuo comercio con aquel poderoso pensamiento teórico. Y no es menos admirable el talento con que articula análisis y reflexiones teóricas en un trabajo crítico coherente como el que he reseñado en estas líneas. 
